\title{
El poder de la imaginación, de la ficción a la acción política. Ideología y utopía en la perspectiva de Paul Ricoeur
}

\author{
The power of the imagination, from fiction to political \\ action. Ideology and utopia in perspective of Paul Ricoeur \\ CRISTHIAN ALMONACID DÍAZ \\ Universidad Católica del Maule, Talca, Chile
}

Artículo recibido: 18 de enero de 2017

Solicitud de revisión: 10 de mayo de 2017

Artículo aceptado: 28 de junio de 2017

Resumen

Paul Ricoeur postula que una teoría de la imaginación se inicia en la literatura y al mismo tiempo es productiva en la vida de la praxis. En la estructura simbólica de la realidad social y política, la imaginación funda el imaginario social, constituye la ideología en su función integradora y suscita la utopía en su función transformadora. En este artículo estudiamos este enfoque, proponiendo el poder de la imaginación como medio de cohesión social y ensayo para la transformación de la realidad, siempre perfectible.

Palabras clave: Ricoeur, imaginación, política, ideología y utopía.

\begin{abstract}
Paul Ricoeur postulates that a theory of the imagination begins in literature and at the same time it is productive in the life of praxis. In the symbolic structure of the social and political reality, the imagination founds the social imaginary, it constitutes the ideology in its integrative function and provokes the Utopia in its charging role. In this article, we study this approach, proposing the power of the imagination as a way of social cohesion and as a test for transformation of reality, always perfectible.
\end{abstract}

Keywords: Paul Ricoeur, imagination, politics, ideology and utopia. 


\section{INTRODUCCIÓN}

Paul Ricoeur postula que una teoría de la imaginación ${ }^{1}$ originada en los textos literarios, puede ser perfectamente productiva y válida si se traslada a la vida de la praxis. Ello nos lleva a pensar que si la imaginación funciona como mediadora entre el pensamiento y la acción (Ricoeur, 2002: 197-218), las transformaciones políticas y sociales serán posibles cuando la imaginación suscite la búsqueda de soluciones en diferentes ensayos ficcionales de lo que no es, pero puede llegar a ser.

Nuestra intención es ubicarnos no en la lógica de una razón fantasiosa, en el sentido de imposible, sino en el desafío de pensar la labor política en otra lógica. Es decir, queremos pensar en un espacio que no nos limite a una descripción de la institucionalidad política, ${ }^{2}$ sino que nos sirva para relacionarnos dialécticamente con una perspectiva que podríamos llamar normativa, que, sin desconocer la historicidad del ser humano, se convierte en el horizonte del ideal del «sí mismo»y de las relaciones intersubjetivas. Postulamos que la actividad política, en su esencia originaria, es pujada a repensarse, imaginando otros modos de hacer política.Y esta es una tarea por hacer porque la sociedad civil exige a las instituciones políticas responder éticamente en las distintas esferas de institucionalidad. En este aspecto, la filosofía práctica y en particular las éticas aplicadas, han realizado su aporte (Cortina \& García Marzá, 2008). Sin embargo, subyace la idea de que no bas-

1 Muchos son los autores que postulan el concepto de imaginación como una clave importante para comprender el pensamiento de Paul Ricoeur. Lelièvre (2014), por ejemplo, menciona a diversos autores que sostienen que la imaginación es una categoría transversal en la obra ricoeuriana. Entre ellos, Richard Kearney, Olivier Abel, Pall Skulason y Marie France Begué. No hay que perder de vista, sin embargo, que el mismo Ricoeur se resiste a pensar su obra como unidad continua y prefiere que se reconozca que su tarea filosófica se compromete más bien con problemas concretos: "No me interesa la alternativa continuo/discontinuo. Lo que creo, o en todo caso lo que puedo decir de mí, es que cada libro está determinado por un problema fragmentario. Me atrae por otro lado mucho la idea de que la filosofía se dirige hacia problemas concretos, hacia obstáculos para el pensamiento bien preciso. [...] Es de otro modo como entiendo el vínculo entre mis distintos libros. Tras haber terminado un trabajo, veo que me enfrento a algo que se me escapa, que huye de su órbita, que deviene para mí en obsesivo y que se constituye en el próximo tema a tratar" (Ricoeur, 2003: 114).

2 En este trabajo hablamos de institucionalidad politica o simplemente politica, para referirnos todas las veces a la actividad que se realiza formalmente dentro de un estado democrático de derecho, legitimado por un aparato de regulación jurídica y administrativa. Estamos ciertos de que en lo tocante a la imaginación se puede aplicar perfectamente al concepto de sociedad civil, entendida como aquella rica estructura ciudadana, no estatal, fundada en recursos morales propios e igualmente legítimos. Cabe señalar, que gracias a autores como J. Habermas. M. Kaldor y J. Keane, entre otros, se ha instalado el concepto de sociedad civil como un elemento imprescindible dentro de la actual discusión filosófica sobre la democracia (García Marzá, 2008: 27-46). Aquí solo nos referimos a la política institucional porque a nuestro juicio es el ámbito de acción democrática que mayormente excluye los recursos imaginativos en su acción. 
ta con enunciar el «deber ser» propugnándolo en discursos políticos, sino que la sociedad civil exige que los deberes ético-políticos se hagan carne, que se expresen en las instituciones para transformarse ellas mismas desde dentro.

Dividimos nuestro trabajo en cinco pasos. En el primero justificamos la relevancia de la imaginación en la dimensión política. En el segundo, describimos cómo la imaginación se conecta con la acción en general y la acción moral en particular. En el tercer paso nos abocamos a leer en Ricoeur el traslado de la imaginación desde su vertiente semántica literaria hasta una teoría de la imaginación en la acción. En un cuarto paso, desarrollamos cómo la imaginación constituye el imaginario social y se concreta en los fenómenos de la ideología y la utopía, para, finalmente, establecer nuestras conclusiones.

\section{LA ACCIÓN POLÍTICA MÁS ALLÁ DE LA ACCIÓN ADMINISTRATIVA, UN DEBER ÉTICO A REALIZAR}

Un primer acercamiento a los acontecimientos que marcan toda acción política en las instituciones democráticas actuales nos permite afirmar dos cosas: primero, la política institucional se concentra las más de las veces en la administración de recursos basada en la exigencia de la optimización económica-técnica. Es decir, estamos ante instituciones políticas cercanas a un sistema de provisión de servicios, distribuidos bajo la exigencia de la igualdad entre los ciudadanos. Y segundo, los países democráticos y liberales en general disponen de una institucionalidad política que aspira a la neutralidad respecto a doctrinas comprehensivas. Dicha aspiración se basa en la idea de que la justicia tiene una primacía sobre las diferentes ideas de bien. En la medida que cualquier idea de bien depende siempre de alguna doctrina comprehensiva, el liberalismo político exige incompatibilidad con la adhesión a un particular empeño de bien. De modo que una concepción política liberal no se involucra con concepciones morales específicas y, consecuentemente, se ajusta a cierto límite que es infranqueable: no cruza la frontera de la vida de los ciudadanos (Rawls, 1996: 208-209).

Tenemos entonces, un modelo de acción política que es operativamente eficaz y razonablemente neutral. Sin embargo, cabe preguntarnos ¿Son los proyectos políticos una mera batería de abastecimientos y cobertura de necesidades básicas sociales? ¿Logra la institucionalidad política comprehensivamente neutra, conseguir la cabal adhesión y por ende la legitimación 
necesaria para su actividad? Desde nuestra perspectiva, esta doble cuestión ha venido a evidenciar una cierta pobreza imaginativa ideológica y utópica en el sentido ricoeuriano (Ricoeur, 1994). Pensamos que la política no puede reducirse a un ejercicio tecnocrático y administrador de recursos, pues también involucra esfuerzos por hacer de la sociedad un lugar para la convivencia, la participación y el desarrollo íntegro de los ciudadanos. En segundo lugar, no es suficiente para la legitimación ciudadana un rol político neutro, pues, aunque se trate a todos los ciudadanos por igual, es exigible también a la institucionalidad «tratar de integrar las diferencias que lo componen» (Cortina, 2010: 34-35).

Es vital una institucionalidad política que no se conforme con una actitud meramente adaptativa, pues una institucionalidad convencida solo de su tarea administrativa y reproductiva es, al fin y al cabo, el descalabro de la legitimidad ciudadana. Esto es así porque la ética, y por supuesto la política dentro de esta, posee una dimensión proyectiva que se encamina hacia un horizonte de justicia, libertad e igualdad como valores por realizar. Como consecuencia, ante la realidad imperfecta de lo dado, la conformidad no puede ser constitutiva de la política, pues si se quiere hacer de la política una actividad digna es necesario que los políticos cumplan su papel, innovando y transformando la realidad. La acción política se redescubre a sí misma si admite entre sus capacidades, a la creatividad y la imaginación para ensayar mundos posibles. Desde nuestro punto de vista, es clave abordar esta capacidad imaginativa y sondear las posibilidades que otorga para las transformaciones políticas que se requieren (Cortina, 1999: 241-252).

\section{CAPACIDAD FICCIONAL Y LA DIMENSIÓN MORAL}

Las posibilidades de ser del hombre, piensa Ortega y Gasset, no son regaladas, hay que inventárselas, sea originalmente, sea por recepción de otros hombres o por recepción del ámbito de la vida en la que somos:

Invento proyectos de hacer y de ser en vista de las circunstancias. Esto es lo único que encuentro y que me es dado: la circunstancia. Se olvida demasiado que el hombre es imposible sin imaginación, sin la capacidad de inventarse una figura de vida, de «idear» el personaje que va a ser. El hombre es novelista de sí mismo, original o plagiario (Ortega y Gasset, 2008: 39).

De tal manera que la presencia de la imaginación en el hombre es un componente que ayuda a explicar el modo como el ser humano se ha adap- 
tado a sus circunstancias y contextos. No se puede reducir la adaptación humana a las características bioquímicas, genéticas y morfológicas que le son propias ya que dicha adaptación también posee un componente cultural, entendida como la capacidad de transmitir experiencias a las generaciones futuras que, recibiendo este legado, utilizan su genio para innovar, creando nuevas formas de adaptación y cambiando el ambiente de un modo diferente a como lo cambia su dimensión biológica. Con esta capacidad, el hombre se anticipa, prevé consecuencias, evalúa campos y caminos de acción, conecta medios y fines, elige alternativas. En palabras de Conill (1991):

Esta herencia cultural cuenta con el lenguaje humano, que no se reduce a un mero medio de comunicación, sino que sirve para pensar e inventar, para referirnos a lo ausente e incluso a lo imaginario. El hombre es un animal de símbolos, bomo significans, portador, hacedor y soportador de símbolos; su capacidad más radical, para muchos, es la simbolización; de ahí que se lo haya considerado como animal estructural, hermenéutico, simbólico (207-208).

La teoría política tampoco se queda exenta de la imaginación. Las teorías contractualistas clásicas de Locke, Rousseau o Kant siempre parten de una hipótesis explicativa o un supuesto inicial anterior a la formalización del contrato social. Las argumentaciones contractualistas apelan a la imaginación para explicar el origen de la vida política. John Rawls, por ejemplo, desarrolla y construye los argumentos de su Teoría de la justicia (1993) sobre la base a su idea de posición original, que no es otra cosa que una situación irreal, supuesta o hipotética que representa un punto de origen desde donde la sociedad acuerda principios a partir de los cuales se obtiene un contrato o acuerdo social:

\footnotetext{
Así pues, hemos de imaginarnos que aquellos que se entregan a la cooperación social eligen, en un acto conjunto, los principios que han de asignar los derechos y deberes básicos y determinar la división de los beneficios sociales. Los hombres habrán de decidir anticipadamente como regularán las pretensiones de unos y otros, y cuáles serán los principios fundamentales de su sociedad (28).
}

Con estas aplicaciones vemos cómo emerge la capacidad imaginativa en el proceso creativo, ya sea a nivel vital, cultural y también teórico-político. Lo que nos lleva a notar que la imaginación es perfectamente posible reconocerla en el ejercicio humano in genere y, por ende, también cuando el hombre se enfrenta a la realización de acciones morales.

Esta necesidad de trasladar la capacidad imaginativa al hecho moral se puede justificar de una manera en particular. Cuando las situaciones a las que se enfrenta el hombre requieren establecer los conductos para resolver 
la mejor acción moral posible. La imaginación permite adelantarse a los hechos, para auxiliarnos cuando nos movemos en un mundo que todavía no es, pero que puede llegar a ser. En este este sentido Ricoeur piensa que la productividad moral del juicio moral y de la acción moral se realiza vía subsunción de las máximas posibles al deber moral universal, complementado con el descenso del juicio moral a la acción y la aplicación de las máximas al caso particular. Ello supondría un doble juego hermenéutico: (1) La interpretación contextualizada de la acción posible y razonable y (2) la reinterpretación de las propias máximas o normas de contenido concreto a la luz del contexto que otorga la aplicación y que exige el reconocimiento de la alteridad de las personas (Ricoeur, 1996: 286-290). Este juego hermenéutico dentro de las circunstancias y en la aplicación de las máximas al caso concreto de la acción, demanda en el agente un ejercicio interpretativo y creativo precisamente porque son múltiples los caminos posibles que se muestran antes de la toma de una decisión y de la realización de la acción.

Pero también la imaginación en la moral es importante en otro sentido que queda implícito en lo que hemos dicho antes. Se necesita imaginar cuando tenemos que considerar que nuestras decisiones morales pueden afectar a terceros. Hay un aspecto que se escapa a la racionalización técnica o moral que, aunque es bastante simple y obvio, suele pasar desapercibido. Una decisión política afecta a personas y ciudadanos que no se conocen, que son invisibles. Solo una capacidad imaginativa que logre visualizar a los afectados abre la posibilidad de empatizar para ponerse en el lugar de quien no se ve en la decisión estratégica (Nussbaum, 1997: 18).

Antes de evaluar y analizar los efectos que la imaginación incorpora en la acción política mediante sus formas de ideología y utopía, quisiéramos establecer en una perspectiva amplia la función de la imaginación en el marco de lo que Ricoeur denomina filosofía de la imaginación (Ricoeur, 1994: 45, 60; Tylor, 2006), que a su vez se requiere leer en vinculación con su filosofía de la metáfora (Ricoeur, 1980). En este caso y en especial por la naturaleza de este trabajo, nos interesa prestar atención al movimiento que realiza Ricoeur, cuando se propone trasladar el fenómeno de la imaginación desde su esencial pertenencia de la noción de innovación semántica discursiva a la esfera práctica y la acción concreta.

Por nuestra parte, cuando hacemos referencia a la ideología no queremos entrar en la discusión de contenidos determinados y cuando hablamos de utopía tampoco queremos ubicarnos en un espacio meramente ilusorio respecto a la realidad. Nuestra intención es reflexionar cómo la imaginación - en sus formas de ideología y utopía - asociada a la acción política, 
permite disponer de posibilidades abiertas para la transformación del statu quo. En este sentido, utilizamos la expresión ideología en su sentido de legitimación e integración social y la expresión utopía como capacidad de reescribir y transformar la realidad. La imaginación se mueve libre a través de la ideología y la utopía más allá de abanderamientos con determinadas opciones políticas, mediando entre el deseo de mejores condiciones de vida política y su realización concreta.

\section{IMAGINACIÓN, SEMÁNTICA Y ACCIÓN}

Una primera contradicción que posee el reconocimiento y la incorporación de la imaginación en la acción política es que la imaginación se presenta como apelación a una capacidad que no es racional lógica. Desde esta visión surge ipso facto un cierto rechazo, desconfianza y desdén. Pues ante una racionalidad estrictamente lógica y metódica la imaginación cuenta del lado de una razón ingenua y débil. Sin embargo, la realidad y su complejidad, el mundo, sus causas y sus efectos distan suficientemente de una pretensión determinante de la racionalidad lógica, pues las estructuras conceptuales racionales no son suficientes para abarcar los entramados de la realidad fáctica. En todo lo que se aprehende, hay siempre algo que se escapa.Ante la realidad superlativa, requerimos reconocernos bajo la efímera irrelevancia del animal cognitivo en el cosmos, que en términos nietzscheanos finge inteligir lo que le rodea para sobrevivir.Tenemos que reconocer que no hay completa y exacta causalidad entre el sujeto y el objeto. Más bien cabe una fuerza mediadora diferente, como la fantasía que despliega el encanto de las metáforas que el mismo mundo ofrece y que nos exige confiar en nuestra intuición como el mejor y más correcto impulso vital (Nietzsche, 2008).

Ricoeur es consciente de la fama negativa de la imaginación. Piensa que la imaginación se ve afectada por la reputación que el término imagen ha adquirido a partir de su abusivo uso en la teoría empirista del conocimiento, cuando se usa como término en la teoría del sentido de la proposición en las filosofías analíticas.También la imaginación adquiere una reputación negativa cuando se usa el concepto imagen en las psicologías de corte conductista entendiéndola como una entidad mental, privada e inobservable. Ricoeur piensa que lo primero que hay que hacer es enfrentar su paradoja y descrédito, para poder hacer un correcto aborde en una investigación 
filosofica. Para comenzar nuestro filósofo recoge cuatro empleos importantes del término imaginación:

a) Se usa para evocar cosas ausentes, pero existentes en otro lugar.

b) Se usa para designar retratos, cuadros o dibujos dotados de existencia física, pero que «toman el lugar» de las cosas que representan.

c) Se llama imagen a las ficciones que evocan cosas inexistentes. En este campo de uso confluyen sueños e invenciones que poseen una mera existencia literaria.

d) Y, finalmente, la imagen se aplica a las ilusiones como representaciones que, para un observador externo, se refieren a cosas inexistentes, pero que para el sujeto que las produce son realidades existentes (Ricoeur, 2002: 199).

Esta distinción ofrece la multiplicidad de sentidos que puede contener la imaginación, pero al mismo tiempo permite distinguir dos lugares de uso del término imagen, con sus respectivas oposiciones. En el lugar del objeto tenemos la imagen en el pensamiento refiriéndose a la percepción de la cosa, de la cual dicha imagen no es más que una huella reproductiva y debilitada de la presencia existente de la cosa sensiblemente captada (Hume, 2004: 53), y en el lado opuesto, tenemos la imagen de cosas ausentes que se hacen presentes a través de retratos, sueños o ficciones literarias, que se convierten en medios por los cuales la conciencia intenta producir cualidades que siempre serán inexistentes en el objeto (Sartre, 1964: 164). ${ }^{3}$ Y en el lugar del sujeto, tenemos imágenes susceptibles de actividad crítica que permiten distinguir lo real de lo imaginario y, en el lado opuesto, tenemos imágenes que son susceptibles de tal nivel de creencia y fascinación, que son confundidas con la realidad, tomándose como reales (Ricoeur, 2002:199-200). Estas serían las raíces que explican el descrédito de la imaginación en la actividad social y política, porque, al fin y al cabo, esta capacidad deformaría la realidad a través de sus formas ideológicas y utópicas.

Para superar estos escollos y descréditos de la imaginación, Ricoeur parte de una tesis que es esencial en su teoría. Se trata de ubicar al pensamiento en general y al pensamiento sociopolítico en particular, dentro de una manera diferente de comprender la relación de dicho pensamiento con la realidad social y la praxis concreta:

3 En el año 1936, Sartre ya había publicado otro ensayo sobre este tema en la misma línea fenomenológica husserliana que lleva por el título, La imaginación (Sartre, 1979). 
Si la realidad social no tuviera ya una dimensión simbólica y, por lo tanto, si la ideología, en un sentido menos polémico o menos negativamente evaluativo, no fuera constitutiva de la existencia social sino que fuera meramente deformadora y desimuladora, el proceso de deformación no podría iniciarse. El proceso de deformación está injertado en una función simbólica. Sólo porque la estructura de la vida social humana es ya simbólica puede deformarse. Si no fuera simbólica desde el comienzo, no podría ser deformada. La posibilidad de deformación es una posibilidad abierta únicamente por esta función (Ricoeur, 1994: 53).

La realidad social entonces es un entramado simbólico originario. Toda posibilidad de hablar sobre un aspecto de la vida social exige movernos primariamente en una estructura simbólica, es decir, siempre a través de usos simbólicos, metafóricos, representaciones y significaciones. A este modo simbólico en que se relaciona nuestro pensamiento con la realidad social podemos acceder de manera privilegiada a través de nuestra capacidad de imaginar:

Hablar de nuestra relación con el mundo exige una estructura simbólica. De ahí que mi principal argumento sea afirmar que si no tenemos desde el comienzo una estructura simbólica en nuestra existencia, nada puede ser deformado. [...] No estamos muy lejos de una inversión completa de nuestro enfoque del problema de lo imaginario. No podríamos comprender que haya imágenes deformadas si no hubiera primero una estructura imaginaria primaria de nuestro estar en el mundo, estructura que está en la base de todas las deformaciones. Lo imaginario se manifiesta no sólo en las formas deformadas de la existencia porque lo imaginario ya está presente en la relación que está deformada. Lo imaginario es constitutivo de nuestra relación con el mundo (Ricoeur, 1994:178).

Esto significa que, si toda condición de existencia social requiere ser representada de una u otra manera siempre, la imaginación mediatiza persistentemente dejando su vestigio, ya sea en el campo de las motivaciones, en nuestro sistema de imágenes respecto a la realidad social que nos une (o des-une) y más profundamente en nuestra representación del mundo, que no puede ser de otra manera, sino primaria y únicamente representado. Las llamadas causas reales nunca se manifiestan como tales en la existencia humana, sino que siempre lo hacen en un modo simbólico, representadas de una forma o de otra (Ricoeur, 1994: 179, 275-285).

Únicamente desde esta comprensión del mundo social entendido como una realidad primariamente simbólica, es posible para Ricoeur sostener su segunda tesis fundamental respecto a la imaginación: que no existe acción sin la imaginación o, dicho de otro modo, que la imaginación media entre el pensamiento y la acción. Veamos como desarrolla Ricoeur esta segunda tesis. 
Para nuestro filósofo la imaginación, dentro de la semántica de la esfera lingüística del discurso metafórico, posee un rol que denomina de resonancia - siguiendo la expresión de Gaston Bachelard- (Ricoeur, 2002: 201), es decir, la imaginación es el medio por el cuál un predicado adquiere una nueva pertinencia significante. Gracias a un movimiento de semejanza desde un predicado en ruinas, emerge un nuevo predicado, súbitamente emergido por una intuición activa (Ricoeur, 1979:131). La asociación de predicados no aparece como mera fusión de átomos mentales dispares, sino como una nueva construcción significante, pues «imaginar es en primer lugar reestructurar campos semánticos» (Ricoeur, 2002: 202). Esta resonancia que la imaginación suscita trae consigo una característica añadida: otorga una nota suspensiva. La imaginación nos faculta para entrar en «un libre juego con las posibilidades, en un estado de no compromiso con respecto al mundo de la percepción o de la acción» (Ricoeur, 2002: 203).

Ahora bien, lo que interesa a nuestro filósofo es saber si se puede trasladar esta resonancia y neutralización de la imaginación desde la esfera lingüística a la esfera de la praxis. Es decir, si es posible que la innovación semántica que inicialmente concurre en los límites de una enunciación metafórica, posea una fuerza referencial ad extra para ser reconocida en las acciones humanas.

Postula Ricoeur que la realidad no solo posee una referencia inmediata gracias a la percepción sensible, sino que también posee una referencia mediata o, como él la denomina, una fuerza referencial de «segundo grado» (Ricoeur, 2002: 204). Ricoeur entiende que el lenguaje poético no solo desdobla al proceso metafórico, sino la referencia misma. Eso quiere decir que en la emergencia de nuevas significaciones predicativas se manifiesta nuestra pertenencia al mundo de la vida, en el que se expresa el contacto de nuestro ser con otros seres y con el ser, más allá de los condicionantes que podríamos llamar materiales reales. Este aspecto es crucial para la imaginación, pues gracias a la ficción, el pensamiento puede dirigirse a ningún lugar respecto a la realidad y al mismo tiempo, desde ese «no lugar», puede volver a redirigirse a la realidad para reescribirla (Ricoeur, 2002: 204). Cualquier transición de la imaginación a la práctica tiene como modelo este principio fundamental: la imaginación y la ficción reescriben la realidad y, por tanto, reescriben las acciones humanas y las acciones políticas. A partir de esta comprensión, la ficción mediante su fuerza heurística se despliega en los proyectos políticos, en las motivaciones para la acción política e incluso en el hacer mismo. Pues la imaginación tiene un rol anticipatorio 
en el juego con los eventuales cursos de acción y con los posibles medios prácticos que harán concreto lo ficcionado:

[...] en lo imaginario ensayo mi poder de hacer, tomo la medida del yo puedo. Sólo me imputo a mí mismo mi propio poder, en tanto soy el agente de mi propia acción, al describírmela con los rasgos de variaciones imaginativas sobre el tema del yo podría, incluso del yo hubiera podido de otra manera, si hubiera querido (Ricoeur, 2002: 207).

Se da un proceso en el que la imaginación está siempre funcionando. Primero en el esquema de los proyectos que se proponen. Pasando por la figuralidad de los deseos que poseen horizontes ilimitados. Hasta las variaciones imaginativas del «yo puedo» que delimitan los horizontes deseados para ajustarse a las condiciones concretas y viables. La imaginación se reconoce como una función general dentro de las posibilidades prácticas que reconfiguran la realidad política. Se articula así una capacidad que es ante todo productiva, pues otorga un carácter extremadamente dinámico y transformador.

\section{LA IMAGINACIÓN DENTRO DEL IMAGINARIO SOCIAL: LA IDEOLOGÍA Y LA UTOPÍA DESDE LA ACCIÓN POLÍTICA}

El punto de partida de Ricoeur para describir los vínculos sociales es el mismo que anotamos antes: la condición imaginativa de la realidad social. Subyace el planteamiento de que la cultura se constituye a partir de un origen conceptual que es en primera instancia simbólico (Ricoeur, 1994: 51, 276). Solo desde la estructura simbólica subyacente la historia cobra sentido, pues los símbolos que alcanzan un estadio común manifiestan el carácter intersubjetivo de la realidad social. Utilizando la teoría husserliana de la instersubjetividad, Ricoeur expresa que existe una idea de historia compartida, porque el campo temporal de cada quien está ligado al campo temporal de otro mediante una relación que se ha denominado de acoplamiento (Paarung) y que permite distinguir que cada quien, no solo posee contemporáneos, sino también predecesores y sucesores (Ricoeur, 2002: 208-209). Mediante la elevación de la categoría del yo pienso kantiano a un principio superior se produce el acoplamiento por analogía, lo que permite, entre otras cosas, la transmisión de las tradiciones:

Es el principio trascendental según el cual el otro es un yo semejante a mí, un yo como yo. La analogía procede aquí por transferencia directa del significado yo. Como yo, mis 
contemporáneos, mis predecesores y mis sucesores pueden decir «yo». Es de esta manera que estoy históricamente vinculado a los demás (Ricoeur, 2002: 209).

Es una imaginación productiva en tanto que constituye el vínculo histórico objetivado en el vínculo social del «nosotros» (Ricoeur, 2002: 210), representado en la institucionalidad política unida a la sociedad civil. El Estado, a través de sus estructuras democráticas, representa el sentido de comunidad histórica de los ciudadanos, resguardando y transmitiendo los símbolos y los relatos para la vida de la memoria histórica colectiva y el sentido de la unidad social (Nussbaum, 2014).

La institucionalidad por esta vía adquiere así una responsabilidad fuerte en la cohesión imaginativa del yo como otro. Si bien este esquema puede resultar bastante abstracto, tanto que se oculta a la experiencia misma, es posible recurrir a las prácticas imaginativas que materializan la constitución del vínculo imaginativo-analógico entre el yo y el otro como semejante. Dichas prácticas políticas se conocen como ideología y utopía. Aunque se ha destacado las más de las veces su sentido patológico y antagónico entre ellas, Ricoeur propone analizarlas en profundidad para poder reconocer su sentido complementario y positivo, poniendo en relación dos fenómenos fundamentales y decisivos en la manera de situarnos en la historia. Nuestro filósofo llama a su análisis de la ideología y la utopía, un «análisis regresivo de significación» (Ricoeur, 1994: 326), pues se trata de una fenomenología genética que sigue la óptica de Husserl desarrollada en su libro Meditaciones cartesianas (1986), para llegar a las significaciones más profundas y fundamentales, haciendo de los conceptos descritos, conceptos más honestos.

\subsection{Ideología}

La crítica hacia la ideología que ha persistido en el tiempo es la realizada por el joven Marx en sus obras tempranas, en especial, en el escrito que compartió con Engels: La ideología alemana (1845-1846). Según Ricoeur, Marx marcó un concepto de ideología que fundó un paradigma dominante en Occidente respecto a su comprensión. Caracterizando «lo real», Marx define a la ideología como «lo no real». Es decir, la ideología no es real porque es contraria a la praxis, entendida como todo aquello que constituyen las condiciones materiales, único requisito desde el cual se puede hablar en propiedad de individuos. Individuos reales y condiciones materiales van unidos intrínsecamente y cualquier forma de abstracción en idea es una 
deformación patológica de la realidad, como una conciencia invertida que produce imágenes invertidas que deforman la realidad:

[...] La ideología alemana es marxista en el sentido de que coloca en el primer plano una base material de entidades anónimas en lugar de las representaciones y fantasías idealistas que giraban alrededor de la conciencia.Ahora la conciencia se considera como algo que está completamente en el campo de la ideología; en la base material real como tal no existe ninguna implicación de la conciencia (Ricoeur, 1994: 110).

A partir de esta antinomia Marx - en oposición a la perspectiva hegeliana- desarrolla un concepto de vida real ligada a los individuos que la materializan. Marx se opone a la historia comprendida en clave hegeliana, esto es, las acciones de los grandes caudillos, militares u hombres de estado como encarnaciones superlativas de un espíritu objetivo. Piensa más bien, que la historia se desarrolla a través del avance en la actividad racional, libre e individual de los hombres en términos de la producción de los medios indispensables para la satisfacción de las necesidades básicas, en la producción de la vida material misma (Marx \& Engels, 1991: 41). En consecuencia, la humanidad no es una conciencia sino, ante todo, individuos reales. Ricoeur insiste en la importancia de esta distinción, porque a su juicio, la oposición entre ideología y realidad es la discusión filosófica marxista primera, diferente a la discusión de las corrientes marxistas posteriores, como la de Althusser por ejemplo, que destacó más la oposición entre la ideología y la ciencia (Ricoeur, 1994: 49, 141-176). En el joven Marx la ideología adquiere su más fuerte sentido patológico, pues se le reduce a un proceso de distorsión y disimulo que oculta el desarrollo de la historia. La ideología como patología es una ilusión que permite proteger el estatuto social y conservar los privilegios de algunos en detrimento de otros.

Sin negar el carácter deformador de la ideología argumentado por Marx, Ricoeur se propone ir un poco más lejos. Es necesario situar el concepto de ideología en una función más fundamental y, sobre todo, mayormente constitutiva de la vida social y política:

¿Por qué no es posible atenerse a este primer concepto de ideología? La metáfora de la inversión oculta a su vez una laguna grave de la explicación. Si se admite que la vida real - la praxis- precede de derecho y de hecho a la conciencia y sus representaciones, no se comprende cómo la vida real puede producir una imagen de sí misma y, con más razón, una imagen invertida. Sólo se puede comprender esto si se percibe en la estructura misma de la acción una mediación simbólica que puede ser pervertida (Ricoeur, 2002:352).

Esto quiere decir que la acción social está llena de lo imaginario antes que se pueda expresar una deformación, pues afirma Ricoeur: «Todas las figu- 
ras de incongruencia deben ser parte de nuestra pertenencia a la sociedad. Creo que esto es cierto hasta el punto de que la imaginación social es parte constitutiva de la realidad social» (Ricoeur, 1994:47). De este modo, la representación patológica de la realidad social es secundaria, porque la realidad social es siempre, primariamente, una representación simbólica. La imaginación es coextensiva al proceso de la praxis. Desde este lugar se abre un nivel originario en el que la ideología pierde su sentido falsificador, pues ninguna sociedad funciona sin reglas simbólicas que son la fuente de la cual bebe la retórica de todo discurso público y político (Ricoeur, 2002:353).

Ricoeur (1994: 275-285) expresa coincidir con Clifford Geertz (1996), al cuestionar que la filosofía marxista no prestó atención a cómo opera la ideología, pasando por alto las razones profundas por las que una determinada realidad social, cualquiera que sea, se transforma en una idea deformada.Tanto para Ricoeur como para Geertz, esta deformación se da por el proceso autónomo de la formulación simbólica de toda acción social.

Siguiendo este argumento, Ricoeur descubre en este proceso simbólico profundo, dos niveles más altos que el mero sentido patológico de la ideología. El nivel de la «legitimación» y el nivel de la «integración».

El nivel de la legitimación - siguiendo términos weberianos- es aquel por el cuál toda sociedad se organiza social y políticamente distinguiendo entre gobernantes y gobernados. Esta relación ineludible marca una distancia que será siempre asimétrica, pues a unos les corresponderá ejercer un poder y a los otros obedecer mediante determinadas estructuras formales. Dentro de esta relación de poder, la autoridad siempre requerirá más legitimidad de la que los ciudadanos están dispuestos a ofrecer. Se crea así un vacío de creencia que posee cualquier sistema político y que de algún modo se debe llenar. Entonces es cuando la ideología entra en juego a través de determinados usos retóricos en el discurso político, que se refrendan en acciones concretas y adquieren un carácter simbólico, al tiempo que aportan la legitimación necesaria y llenan la brecha de creencia que posee cualquier tipo de autoridad - sea democrática o no- en su ejercicio de poder político (Ricoeur, 1994: 228-230).

En el nivel de la integración social, una sociedad se integra como un todo político gracias a la identificación y adhesión que los ciudadanos sienten por un marco simbólico reflejado en las conmemoraciones, los relatos fundacionales o las narraciones de cosmovisiones compartidas. Esta integración a partir de la ideología posee un lugar que no solo es espacial, sino también temporal. La historia, el recuerdo de los padres fundadores o los hechos pasados de un grupo es extremadamente importante, pues son he- 
chos que se transmiten como tradición a partir de un proceso que siempre es ideológico, pero actuando en positivo como una estructura integradora (Ricoeur, 1994: 281). Aquí la función de la ideología será «difundir la convicción de que esos acontecimientos fundadores son constitutivos de la memoria social, y a través de ella, de la identidad misma de la comunidad» (Ricoeur, 2002:354). El acto fundador por este medio se revive, se reactualiza mediante interpretaciones que se remodelan en la conciencia colectiva. Todo grupo social mantiene consistencia gracias a esta imagen estable que imagina, expresando con ello un nivel más alto del fenómeno ideológico.

La relación de interdependencia de estos tres niveles: el patológico, la legitimación y la integración, si bien hemos destacado su carácter positivo, puede también adquirir una retroalimentación negativa. Un proceso integrador conmemorativo puede marcar el proceso de legitimación de la autoridad y mediante una clave interpretativa interesada y parcial, adquirir una forma artificial y débil, convirtiéndose a la postre en un elemento que justifique un código universal de interpretación de los acontecimientos del mundo, deformando la realidad. La tarea ética de la institucionalidad política en este caso es preservar la función integradora de la memoria colectiva, para no deformar el aspecto constructivo de la ideología.

\subsection{Utopía}

Como dijimos, la utopía y la ideología son géneros de la imaginación, pues sus funciones expresan una estructura similar; sin embargo, tenemos que reconocer que estamos ante fenómenos diferentes. Una diferencia, por ejemplo, es que la utopía es un género declarado por sus autores (Tomás Moro en 1516), mientras que para la ideología no existe relación de autoría, pues nadie se adjudica ser propugnador de un determinado contenido ideológico.

Como se sabe, la palabra utopía en su significado etimológico, hace referencia a un «no lugar»o «ningún lugar». Desde ese significado la utopía adquiere ipso facto un sentido patológico, pues refiere la más de las veces a la evasión y la huida respecto a la realidad contingente. De hecho, la misma crítica que se hace desde el pensamiento marxista a la ideología se aplica a la utopía, pues aquello que es utópico se aleja de la realidad al desvanecer lo real en la frontera de lo irrealizable.

Ricoeur se esmera en desentrañar la función de la utopía citando a Karl Mannheim: Ideología y utopía (1973; Ricoeur, 1994: 291, 301). La contribu- 
ción de Mannheim, según Ricoeur, se puede sintetizar en tres aspectos: suministra un concepto, guía la distinción entre diferentes formas de utopía y expresa el carácter irreductible de esta tipología. Mannheim se esfuerza por disponer argumentos para afirmar su idea principal: la utopía posee un proceso de declinación y progresiva desaparición por la incongruencia que ella expresa respecto a la realidad, debido a que las personas se ajustan cada vez más a la realidad tal como ella es. Sin embargo, para Ricoeur la utopía expresa, en su sentido más profundo, una fuerza imaginativa transformadora. Las ficciones resultan interesantes, no porque son meros sueños lejanos a la realidad, sino porque pueden dar forma a una nueva realidad al permitir reescribir la vida (Ricoeur, 1994: 324). Esto significa que la utopía expresa todas las potencialidades que un grupo social determinado posee para pensar de otros modos el orden social establecido. En este sentido la utopía exige justificar, cambiar lo que haya que cambiar y democratizar las diferentes perspectivas que se incuban en el seno de las complejidades sociales. Por esta razón para Ricoeur la utopía guarda un sentido positivo dentro de sí, pues la utopía permite abrir horizontes gracias a la capacidad que posee de concebir lugares vacíos e inexistentes desde los cuales se puede volver la mirada a la realidad (Ricoeur, 1994: 58).

La utopía se convierte así en la contrapartida de la ideología pues esta cierra el pasado conservando los hechos fundacionales y conmemorativos, mientras que la utopía abre el futuro al poner en entredicho lo presente, cuestionando lo que ya está dado. Por otro lado, la ideología es el medio por el cuál la autoridad se legitima, mientras que la utopía es el medio por el cuál la autoridad se deslegitima al permitir que entren en juego las variaciones imaginativas respecto del poder político. Y, por último, cuando la ideología en su nivel más alto integra, la utopía en su nivel más alto origina la subversión que permite representar reivindicaciones que se acumulan en la imaginación como expectativas para inaugurar etapas políticas (Torreblanca, 2015) y cambios sustantivos:

Imaginar el no lugar es mantener abierto el campo de lo posible. $\mathrm{O}$, para conservar la terminología que hemos adoptado en nuestra meditación acerca del sentido de la historia, la utopía es lo que impide al horizonte de expectativa fusionarse con el campo de la experiencia. Es lo que mantiene la distancia entre la esperanza y la tradición (Ricoeur, 2002: 359).

Al ubicarse en un punto intermedio entre la tradición y la esperanza, la subversión utópica no es compatible con la violencia, pues la utopía es una representación imaginativa que es capaz de convencer por medio de la 
razón como por el sentimiento. La utopía posee estructuras de razón en la medida que su poder se traslada a los ciudadanos intelectuales y ciudadanos de ciencia, tal como lo descubre Ricoeur en la perspectiva de Saint-Simon (Ricoeur, 1994: 303-316). Es la racionalidad ilustrada la que es al mismo tiempo utópica, pues la razón - bomo sapiens - es portadora radical de la protesta sobre el statu quo. Esta racionalidad ilustrada y utópica se materializa por medio de la colaboración de ciudadanos industriales en el sentido de laboriosos - bomo faber. Por otra parte, la utopía sigue estructuras emotivas tal como lo expresa Fourier (Ricoeur, 1994: 317-328). De esta forma, la utopía se mueve en la línea de la motivación y su fuerza la aporta la imaginación vía ciudadanos artísticos. Como lo demuestra la reflexión desde Hobbes hasta Hume, el orden social está construido más sobre pasiones compartidas que sobre las ideas. Por ejemplo, la pasión de «alternar», como necesidad emotiva de variar, sea en las ocupaciones de cada quien o en las relaciones políticas con los demás, para la multiplicación de participantes. O la pasión por las riquezas espirituales como apertura a necesidades no materiales. O la pasión por las intrigas que se crean mediante inteligencia y astucia para acontecer en hechos, suscitando el interés y creando la tensión que siempre es saludable para la actividad política democrática.

\section{CONCLUSIONES}

La imaginación cobra su relevancia en la actividad política en la medida que descubrimos la estructura simbólica de la realidad social. La imaginación se mueve forzosamente dentro de todo hecho social porque las relaciones intersubjetivas siempre poseen significación, más allá de determinadas medidas cuantitativas o estadísticas que son los recurrentes medios de aborde burocrático del hecho social y político.

Por esta razón, el esfuerzo filosófico que Paul Ricoeur hace para trasladar la capacidad de imaginar desde la literatura a la praxis no es en vano. De este traslado surge la actividad de los fenómenos imaginativos de la ideología y la utopía que, aunque las más de las veces se destaque su componente patológico, requieren un tratamiento de análisis que permita descubrir su sentido positivo. Mientras la ideología permite la conservación de determinadas tradiciones integradoras de lo social en un sentido reproductor, la utopía abre nuevos horizontes de realización política en un sentido productor. El entrecruzamiento de estos fenómenos en la actividad política se basa en una tensión permanente entre la función integradora de 
la ideología y la función de subversión de la utopía. La proyección desde otro lugar como un «no lugar» permite impugnar la tendencia petrificante de la ideología y, a su vez, el carácter integrador de la ideología permite curar la enajenación de la utopía, otorgando una identidad más estable a la comunidad histórica. Soñar nuevas formas de estructura política requiere haber conquistado interpretaciones nuevas de las tradiciones desde las que se procede.Y la identidad común reclama conciencias políticas que permitan verse a sí mismas desde un no lugar, para movilizar estructuras sociales siempre perfectibles.

Evidentemente, la mediación simbólica desde la que se constituye la sociedad puede ser un arma de doble filo. La deformación y la evasión pueden constituir un daño a las estructuras políticas democráticas. La imaginación es como la fusión nuclear que puede convertirse en una bomba destructiva o energía alternativa. La diferencia será determinada por el uso que se le quiera dar según las intenciones responsables de los agentes. De esta manera, pensamos en dos responsabilidades que se pueden extraer del entramado simbólico del imaginario social.

En primer lugar, las instituciones políticas se hacen oficialmente responsables de los símbolos y relatos que constituyen la cohesión social. Emerge desde aquí un deber ético en la conservación de la memoria histórica de la comunidad, en la transmisión de los valores políticos que sustentan la integración y la transformación de la realidad. La coherencia política es para ello una clave fundamental. Por ejemplo, una comunidad política que desea elevar un sentido de solidaridad como signo de una identidad colectiva, requiere un sistema fiscal que en concreto posea un sistema recaudador y distributivo que manifieste una compasión equilibrada y apropiadamente justa hacia los ciudadanos.

En segundo lugar, un agente político preparado requiere conocer la historia de su propio país, estar contactado con la experiencia simbólica de sus contemporáneos, con las tradiciones ideológicas y políticas que moldean el ambiente político. No basta que conozca la esfera jurídica, sino también necesita un conocimiento cabal de las relaciones sociales, base de la estructura institucional. Este conocimiento se enriquece con una acción política que se encuentra en medio de los afectados, relacionándose permanentemente con los ciudadanos para recoger todas las iniciativas de la sociedad y hacerlas viables.

Como hemos tratado de mostrar, el pensamiento a través de la imaginación no produce cosas como si fuera un acto mágico. La imaginación permite producir cambios partiendo desde la realidad, pues no se transforma 
la nada. Se requiere partir desde lo dado, observándolo desde puntos de vista diferentes. La imaginación en esta perspectiva se anticipa a la realidad, juega con las posibilidades de acción y se convierte en un medio capacitante de cambio.

La imaginación nos permite distinguir entre la rutina de los asuntos de estado y la Política, en mayúscula. La rutina de los asuntos de estado se desarrolla en la habitual y necesaria administración política resuelta en la aplicación de la reglamentación jurídica y constitucional existente. Mientras que la Política emerge cuando la acción política tiene que moverse en lugares que no existen, es decir, cuando se elaboran proyectos, que deciden e implementan novedades en la estructura institucional, promoviendo los consensos e incorporando las innovaciones. Cuando hay que crear institucionalidad es cuando la imaginación se vuelve un recurso rotundo. En la Política, la racionalidad política se concilia con la imaginación tanto en su faceta reproductiva como en su faceta productiva.

\section{BIBLIOGRAFÍA}

Cortina, Adela \& García Marzá, Domingo (2008). Razón pública y éticas aplicadas. Madrid:Tecnos.

Cortina, Adela (1999). El comunitarismo universalista de la filosofía kantiana. En Carvajal Cordón, Julián (coord.). Moral, derecho y política en I. Kant (241-251). Cuenca: Ediciones de la Universidad de Castilla-La Mancha.

Cortina, Adela (2010). Justicia cordial. Madrid:Trotta.

Conill, Jesús (1991). El enigma del animal fantástico. Madrid:Tecnos.

García-Marzá, Domingo (2008). Sociedad civil: una concepción radical. Recerca. Revista de Pensament i Anàlisi, 8, 27-47.

Geertz, Clifford (1996). La interpretación de las culturas. Barcelona: Gedisa. (Alberto L. Bixio trad.).

Hume, David (2004). Investigación sobre el entendimiento bumano. Madrid: Istmo. (Vicente Sanfélix y Carmen Ors, trads.).

Husserl, Edmund (1986). Meditaciones cartesianas. Madrid:Tecnos. (Mario Presas, trad.).

Lelièvre, Samuel (2014). Reseña de la obra: Amalric, Jean-Luc (2013) Paul Ricour, l'imagination vive. Une genèse de la philosophie ricourienne de l'imagination. París: Hermann. En Études Ricouriennes / Ricœur Studies, vol 5, 2, 132-136. 
Mannheim, Karl (1973). Ideología y utopía. Introducción a la sociología del conocimiento. Madrid:Aguilar. (Eloy Terrón, trad.).

Marx, Karl \& Engels, Friedrich (1991). La ideología alemana. Feuerbach, contraposición entre la concepción materialista y la idealista. València: Educació. Materials de Filosofía, Universitat de València. (Wenceslao Roces, trad.).

Nietzsche, Friedrich (2008). Sobre verdad y mentira en sentido extramoral. Madrid:Tecnos. (Luis Valdés y Teresa Orduña, trads.).

Nussbaum, Martha Craven (1997). Justicia poética. La imaginación literaria y la vida pública. Santiago de Chile: Editorial Andrés Bello. (Carlos Gardini, trad.).

Nussbaum, Martha Craven (2014). Emociones políticas ¿Por qué el amor es importante para la justicia? Madrid: Paidós. (Albino Santos, trad.).

Ortega y Gasset, José (2008). Historia como sistema y otros ensayos de filosofía. Madrid: Revista de Occidente en Alianza Editorial.

Rawls, John (1993). Teoría de la justicia. México: FCE. (María Dolores González, trad.).

Rawls, John (1996). El liberalismo político. Barcelona: Crítica. (Antoni Domènech, trad.).

Ricoeur, Paul (1979). The function of fiction in shaping reality. Man and World, vol. 12, 2, june, 123-141.

Ricoeur, Paul (1980). La metáfora viva. Madrid: Cristiandad. (Agustín Neira, trad.).

Ricoeur, Paul (1994). Ideología y utopía. Barcelona: Gedisa. (Alberto L. Bixio, trad.).

Ricoeur, Paul (1996). Sí mismo como otro. Madrid: Siglo XXI. (Agustín Neira Calvo trad.).

Ricoeur, Paul (2002). Del texto a la acción. Ensayos de bermenéutica II. México: FCE. (Pablo Corona, trad.).

Ricoeur, Paul (2003). Crítica y convicción. Madrid: Síntesis. (Javier Palacio Tauste, trad.).

Sartre, Jean Paul (1964). Lo imaginario: psicología fenomenológica de la imaginación. Buenos Aires: Losada. (Manuel Lamana, trad.).

Sartre, Jean Paul (1979). La imaginación. Barcelona: Edhasa. (Carmen Dragonetti, trad.).

Torreblanca, José Ignacio (2015). Asaltar los cielos. Podemos o la política después de la crisis. Barcelona: Debate.

Tylor, George H. (2006). Ricoeur's Philosophy of Imagination. Journal of French Philosophy, vol. 16, 1 y 2, Spring-Fall. doi: 10.5195/jffp.2006.186 